\title{
Hypericin-bearing magnetic iron oxide nanoparticles for selective drug delivery in photodynamic therapy
}

This article was published in the following Dove Press journal:

International Journal of Nanomedicine

12 November 2015

Number of times this article has been viewed

\author{
Harald Unterweger' \\ Daniel Subatzus' \\ Rainer Tietze \\ Christina Janko' \\ Marina Poettler' \\ Alfons Stiegelschmitt ${ }^{2}$ \\ Matthias Schuster ${ }^{3}$ \\ Caroline Maake ${ }^{4}$ \\ Aldo R Boccaccini ${ }^{5}$ \\ Christoph Alexiou' \\ 'ENT Department, Section of \\ Experimental Oncology and \\ Nanomedicine (SEON), Else Kröner- \\ Fresenius-Stiftung Professorship, \\ University Hospital Erlangen; \\ ${ }^{2}$ Institute of Glass and Ceramics, \\ Department of Materials Science and \\ Engineering, University Erlangen- \\ Nuremberg, ${ }^{3}$ Materials for Electronics \\ and Energy Technology, Department \\ of Materials Science and Engineering, \\ University Erlangen-Nürnberg, \\ Erlangen, Germany; ${ }^{4}$ Institute of \\ Anatomy, University of Zurich, \\ Winterthurerstr, Zurich, Switzerland; \\ ${ }^{5}$ Institute of Biomaterials, Department \\ of Materials Science and Engineering, \\ University Erlangen-Nuremberg, \\ Erlangen, Germany
}

Correspondence: Christoph Alexiou ENT-Department, Section of Experimental Oncology and Nanomedicine, HNO Klinik, Else Kröner-Fresenius-Stiftung Professorship, University Hospital Erlangen, Waldstraße I I, 91054 Erlangen, Germany

$\mathrm{Tel}+4991318534769$

$\mathrm{Fax}+49$ 9|3| 8534808

Email c.alexiou@web.de
Abstract: Combining the concept of magnetic drug targeting and photodynamic therapy is a promising approach for the treatment of cancer. A high selectivity as well as significant fewer side effects can be achieved by this method, since the therapeutic treatment only takes place in the area where accumulation of the particles by an external electromagnet and radiation by a laser system overlap. In this article, a novel hypericin-bearing drug delivery system has been developed by synthesis of superparamagnetic iron oxide nanoparticles (SPIONs) with a hypericin-linked functionalized dextran coating. For that, sterically stabilized dextran-coated SPIONs were produced by coprecipitation and crosslinking with epichlorohydrin to enhance stability. Carboxymethylation of the dextran shell provided a functionalized platform for linking hypericin via glutaraldehyde. Particle sizes obtained by dynamic light scattering were in a range of 55-85 nm, whereas investigation of single magnetite or maghemite particle diameter was performed by transmission electron microscopy and X-ray diffraction and resulted in approximately $4.5-5.0 \mathrm{~nm}$. Surface chemistry of those particles was evaluated by Fourier transform infrared spectroscopy and $\zeta$ potential measurements, indicating successful functionalization and dispersal stabilization due to a mixture of steric and electrostatic repulsion. Flow cytometry revealed no toxicity of pure nanoparticles as well as hypericin without exposure to light on Jurkat T-cells, whereas the combination of hypericin, alone or loaded on particles, with lightinduced cell death in a concentration and exposure time-dependent manner due to the generation of reactive oxygen species. In conclusion, the combination of SPIONs' targeting abilities with hypericin's phototoxic properties represents a promising approach for merging magnetic drug targeting with photodynamic therapy for the treatment of cancer.

Keywords: magnetic drug targeting, photodynamic therapy, SPION, hypericin

\section{Introduction}

One of the most promising approaches for cancer treatment in the last few years is magnetic drug targeting (MDT) ${ }^{1-3}$ In this concept, drug accumulation in the tumor can be achieved with a drug-loaded magnetic carrier system, which is physically directed to the region of interest by an external magnetic field. ${ }^{4,5}$ In comparison to conventional drug administration, this leads to an effective increase in the drug concentration in the affected tissue as well as a reduced drug concentration in the rest of the body. 6,7 Thus, a decrease in systemic side effects, such as nausea, hair loss, or neurotoxicity, can be achieved. ${ }^{8-10}$

An interesting feature of MDT is that it can be combined with other cancer treatment strategies such as photodynamic therapy (PDT), to create an even more selective treatment. Magnetic particles that are commonly used for MDT are superparamagnetic iron oxide nanoparticles (SPIONs), including magnetite $\left(\mathrm{Fe}_{3} \mathrm{O}_{4}\right)$, 
maghemite $\left(\gamma-\mathrm{Fe}_{2} \mathrm{O}_{3}\right)$, or other ferrites. ${ }^{11-13}$ They are biocompatible and have superparamagnetic characteristics depending on their size, which leads to an extensive use of these particles in bioseparation, hyperthermia, magnetic resonance imaging, and drug targeting. ${ }^{6,14-19}$ SPIONs have a large surface-area-to-volume ratio, which is the reason why they tend to agglomerate in order to reduce their surface energy. ${ }^{20}$ To prevent the particles from this behavior, we used dextran as a stabilizing agent. It is a biocompatible, biodegradable, and water-dispersible branched polysaccharide. ${ }^{21,22}$ Additionally, the hydroxyl groups of this polymer can be used to add various functionalities, which can then be further used to link the photosensitizer (PS), in our case, hypericin. ${ }^{23}$

Hypericin, a naturally occurring PS, is an essential component of the plant Hypericum perforatum, also known as St John's wort. Besides its natural extraction, hypericin can also be synthesized as described by Karioti and Bilia. ${ }^{24}$ As a derivative of the anthraquinone, hypericin consists of aromatic rings that form a planar molecule. Its delocalized $\pi$-electron system is responsible for the photoactive behavior, which is used in PDT (Figure 1). There, upon activation by light, PS transfers its energy to other molecules finally generating highly reactive oxygen species (ROS). In the vicinity of cell components, these intermediates cause biological damage by oxidation. ${ }^{25}$ Usually, the PS such as hypericin is applied systemically, which leads to a high systemic photosensitivity accompanied by a high rate of discomfort to the patients. Hence, the combination of MDT with PDT can reduce this disadvantage and result in a high selectivity as well as significant fewer side effects, since the therapeutic treatment only takes place in the area where the accumulation of the particles due to the external magnet and the radiation by a laser system overlap.
In this work, we describe a novel approach, where such a drug delivery vehicle is designed based on the combination of MDT and PDT.

\section{Materials and methods Materials}

Chemicals for the iron oxide nanoparticles synthesis, acetic acid (water free), acetonitrile (HPLC gradient grade), ethanol (HPLC gradient grade), methanol (MeOH, HPLC gradient grade), MUSE count and viability assay kit, sodium dihydrogen phosphate, as well as sterile and unsterile Rotilabo ${ }^{\circledR}$ syringe filters with cellulose mixed ester membrane have been provided by Carl Roth (Karlsruhe, Germany) and Merck (Darmstadt, Germany), respectively.

Dextran from Leuconostoc spp. (molecular weight $=$ $6 \mathrm{kDa})$, epichlorohydrin (ECH), ammonium acetate, chloroacetic acid, $2^{\prime}, 7^{\prime}$-dichlorofluorescein diacetate (DCFH-DA), ethyl chloroformate, as well as phosphate buffered saline (PBS) were purchased from Sigma-Aldrich (Hamburg, Germany). Sulfosalicylic acid solution (20\%) was obtained from AppliChem (Darmstadt, Germany). RPMI 1640 medium, F-12K medium, L-glutamine, Hoechst 33342 (Hoe), Annexin A5-Fitc (AxV), and hexamethylindodicarbocyanine iodide dye (DiI) were purchased from Thermo Fisher Scientific (Waltham, MA, USA). Hypericin was purchased from Alfa Aesar (Karlsruhe, Germany), and fetal calf serum (FCS) and L-glutamine from Biochrom (Berlin, Germany). Ringer's solution containing $0.9 \% \mathrm{NaCl}$ (w/v) was supplied by DeltaSelect (Rimbach, Germany). SPECTRA/POR ${ }^{\circledR} 6$ dialysis tubing with a molecular weight cut-off (MWCO) of $10 \mathrm{kDa}$ and a diameter of $29 \mathrm{~mm}$ was purchased from Serva Electrophoresis (Heidelberg, Germany). Vivaspin 20 ultrafiltration units with $100 \mathrm{kDa}$ MWCO were supplied by Sartorius Stedim Biotech

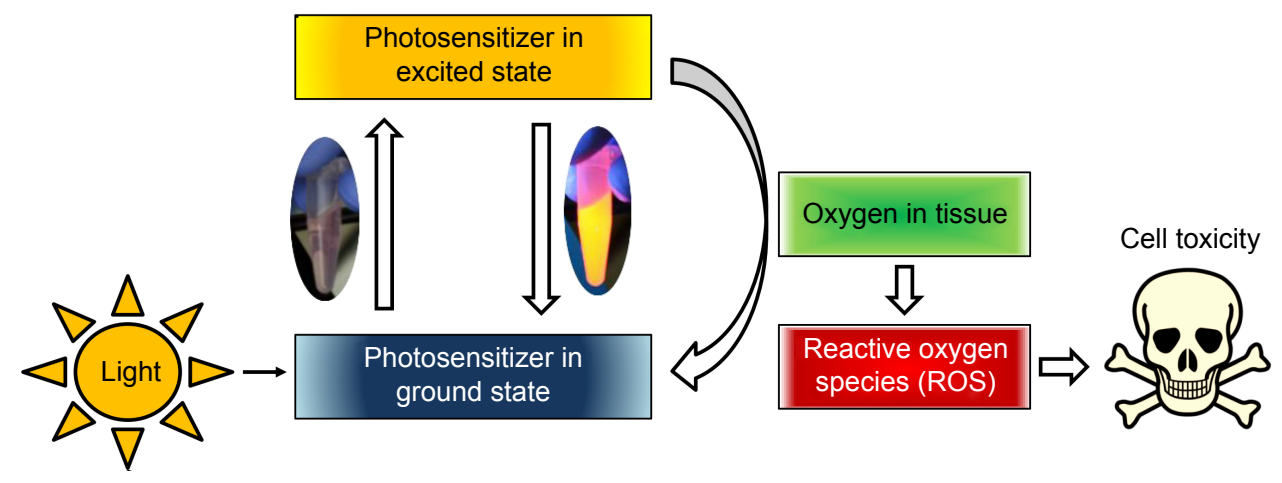

Figure I Schematic representation of principle of photodynamic therapy: a photosensitizer is excited by an external light stimulus.

Note: This energy can be transferred to oxygen in tissue, which leads to the formation of reactive oxygen species, causing oxidation of cellular components (eg, proteins, lipids, and DNA) and finally cell death. 
(Goettingen, Germany). Water used in all experiments was of bidistilled quality.

\section{Preparation of functionalized dextran-coated SPIONs}

Dextran-coated SPIONs (SPION ${ }^{\text {DEX }}$ ) were synthesized in a cold gelation process, as described previously. ${ }^{26}$ In brief, an aqueous solution containing $8.8 \%(\mathrm{w} / \mathrm{w})$ dextran, 2.4\% (w/w) $\mathrm{FeCl}_{3} \cdot 6 \mathrm{H}_{2} \mathrm{O}$, and $0.9 \%(\mathrm{w} / \mathrm{w}) \mathrm{FeCl}_{2} \cdot 4 \mathrm{H}_{2} \mathrm{O}$ was prepared and filtered through a $0.22-\mu \mathrm{m}$ membrane into an ice-cooled three-neck round-bottomed flask. Under an argon atmosphere, the temperature was adjusted to $0^{\circ} \mathrm{C}-4^{\circ} \mathrm{C}$. $\mathrm{NH}_{3}$ was added to the solution, which resulted in a green-brownish suspension. After heating the solution at $75^{\circ} \mathrm{C}$, the formed particles were cooled and dialyzed against water (MWCO $10 \mathrm{kDa}$ ) to remove excess salts. Redundant dextran was removed afterward by ultrafiltration in a centrifuge 5430R (Eppendorf, Hamburg, Germany) with Vivaspin20 filter units at $6,300 \times g$ for 10 minutes for multiple runs. The dextran molecules of the SPION coating were crosslinked with ECH. In this reaction, the $\mathrm{pH}$ of the particles was adjusted to basic conditions with $5 \mathrm{M} \mathrm{NaOH}$ and then $\mathrm{ECH}$ was added to a final concentration of $15 \%(\mathrm{v} / \mathrm{v})$. The suspension was stirred for 24 hours and then it was again dialyzed against water for 24 hours, followed by ultrafiltration and sterile filtration through $0.22 \mu \mathrm{m}$ filters.

The dextran coating of the particles was functionalized with carboxylic acid groups according to Huynh et al. ${ }^{23}$ Briefly, the $\mathrm{pH}$ of the suspension was adjusted to $12-13$ with $5 \mathrm{M} \mathrm{NaOH}$. After cooling the suspension, monochloroacetic acid was added and then it was heated to $60^{\circ} \mathrm{C}$ for 90 minutes, followed by neutralization with acetic acid. In the end, the particles were purified by dialysis against water and ultrafiltration. In the following, they are referred to as SPION ${ }^{\mathrm{CMD}}$.

The determination of the particles' iron content was performed photometrically as described by Dokuzovic. ${ }^{27}$

\section{Linking of hypericin to functionalized SPIONs}

Hypericin was covalently bound to SPION ${ }^{\mathrm{CMD}}$ via glutaraldehyde (GA). First of all, a 1\% GA solution was prepared by diluting a commercial 25\% GA stock solution with $10 \mathrm{mM}$ phosphate buffer solution, and the particulate suspension was buffered with $10 \mathrm{mM} \mathrm{NaH} \mathrm{PO}_{4}$. Buffered suspension (5 mL) was mixed with $838 \mu \mathrm{L} 1 \%$ GA and stirred for 1 hour. Thereafter, an equal volume of hypericin $(50 \mu \mathrm{g} / \mathrm{mL}$ in $\mathrm{MeOH}$ ) was added and stirring was continued for further 23 hours. The resulting samples were dialyzed against water to remove excess GA.
For the removal of unbound hypericin from the samples, a method was developed, based on different solubilitybehaviors of hypericin and SPION ${ }^{\mathrm{CMD}}$ in alcoholic medium. While hypericin shows very good solubility in $\mathrm{MeOH}$, SPION ${ }^{\mathrm{CMD}}$ precipitates if $\mathrm{MeOH}$ content in the suspension is too high. Therefore, samples were diluted with $\mathrm{MeOH}$ until precipitation occurred and sedimentation was accelerated in a $5430 \mathrm{R}$ centrifuge at $7,200 \times g$. As a result, SPION ${ }^{\text {CMD-Hyp }}$ deposited on the bottom and excess hypericin could be removed by decantation. The samples were refilled with $\mathrm{MeOH}$ to their original volume and dispersed by ultrasonification (ultrasonic finger Sonopuls, Bandelin, Germany) for 30 seconds, before they were centrifuged again at 7,200× $g$ for 10 minutes. This step is repeated five times, until the supernatant becomes clear. Finally, the samples were resuspended in water by ultrasonification ( $75 \mathrm{~W}$ for 30 seconds), which resulted in a stable colloid, and is referred to as SPIONCMD-Hyp.

\section{Particle size and $\zeta$ potential measurement}

The hydrodynamic size of the nanoparticles was acquired by dynamic laser scattering with a Nanophox (Sympatec, Clausthal-Zellerfeld, Germany) operated in cross-correlation mode. For the $\zeta$ potential measurements (Nanosizer ZS, Malvern Instruments, Herrenberg, Germany), which were performed at $\mathrm{pH} 7$ and $25^{\circ} \mathrm{C}$ with a scattering angle of $90^{\circ}$, particles were dispersed in aqueous solutions. The experiments were performed in triplicates and, the results were averaged.

\section{Fourier transform infrared spectroscopy}

The chemical composition of lyophilized nanoparticle specimens was determined with the ALPHA FT-IR spectrometer (Bruker Corporation, Billerica, MA, USA). The spectra were collected in attenuated total reflection mode in the mid-infrared region from 4,000 to $400 \mathrm{~cm}^{-1}$, with a step size of $0.5 \mathrm{~cm}^{-1}$.

\section{Determination of hypericin content}

Prior to the determination of the hypericin content in drugloaded samples, nanoparticles had to be dissolved in acidic conditions at $99^{\circ} \mathrm{C}$. Then, quantification of hypericin was done by high-performance liquid chromatography (HPLC), combined with an electrospray-ionization mass spectrometer. As a stationary phase, an XBridge Shield RP18 column (Waters, Milford, MA, USA) with a particle size of $3.5 \mu \mathrm{m}$, an interior diameter of $3.0 \mathrm{~mm}$, and a length of $100 \mathrm{~mm}$ was used at a temperature of $30^{\circ} \mathrm{C}$. The mobile phase consisted of acetonitrile, $\mathrm{MeOH}$, and $20 \mathrm{mM}$ ammonium acetate in 
a volume ratio of 54:36:10 and was used with a flow rate of $1.0 \mathrm{~mL} / \mathrm{minute}$. The HPLC device was a Waters e2695 series and the mass spectrometer was a Waters Acquity SQ detector (both Milford, MA, USA), with a desolvation temperature of $450^{\circ} \mathrm{C}$ and detecting a mass-to-charge ratio of 503 in ESI(-)-mode. Based on the reference samples, a linear calibration curve can be achieved, showing the dependence of hypericin concentration as a function of peak area and thus can be used to calculate the hypericin content of the particulate specimens. All measurements were performed in triplicates and the results were averaged.

\section{Transmission electron microscopy}

Transmission electron microscopy (TEM) images were taken by a CM300 UltraTWIN transmission electron microscope (Philips, Eindhoven, the Netherlands) operating at $300 \mathrm{kV}$ in imaging mode. Samples were prepared by drop cast of a $10 \mu \mathrm{L}$ aliquot of a diluted nanoparticle solution, on an Athene $^{\circledR}$ grid (Plano GmbH, Wetzlar, Germany). The size distribution is determined by examination of an overview TEM image with the software ImageJ (version 1.48; National Institutes of Health, Bethesda, MD, USA).

\section{X-ray diffraction}

In this study, a Siemens D500 (Bruker AXS Inc., Madison, WI, USA) X-ray diffraction (XRD) device is used to perform a $\theta / 2 \theta$-measurement in order to determine the interplanar distances $d_{h k l}$ and therefore the crystallinity of the samples. Lyophilized particles were mounted onto a sample holder. The $\mathrm{Cu} \mathrm{K} \mathrm{K}_{\alpha}$ beam with the wavelength $\lambda=0.15418$ $\mathrm{nm}$ was used as an X-ray source and the angular range was $25^{\circ}-70^{\circ}$ with a step size of $0.02^{\circ} /$ second and a dwell time of 1 second. Afterwards, the interplanar spacing was determined by Bragg's law (1) and the lattice parameter $a$ by Equation 2:

$$
\begin{gathered}
d_{h k l}=\frac{\lambda}{2 \sin \theta} \\
d_{h k l}=\frac{a}{\sqrt{h^{2}+k^{2}+l^{2}}}
\end{gathered}
$$

with $\theta$ as the diffraction angle and $h, k$, and $l$ as the Miller indices of the diffraction plane.

According to the Debye-Scherrer formula, the crystallite size $d_{\mathrm{XRD}}$ for the sample is given by:

$$
d_{\mathrm{XRD}}=\frac{0.9 \lambda}{\beta \cos \theta}
$$

where $\beta$ is the full-width at a half maximum value of XRD diffraction peaks.

\section{In vitro toxicity}

\section{Cell line and culture condition}

The in vitro toxicity of free and particle-bound hypericin was investigated in the nonadherent human T-cell leukemia cell line Jurkat (ACC 282, DSMZ, Braunschweig, Germany), cultured in RPMI 1640 medium supplemented with 10\% FCS and $1 \%$ glutamine. Cells were cultured in a $\mathrm{CO}_{2}$ incubator (INCOmed, MEMMERT, Schwabach, Germany) at $37^{\circ} \mathrm{C}$, $95 \%$ humidified air and $5 \% \mathrm{CO}_{2}$.

\section{Analysis of Jurkat cells using flow cytometry}

Before beginning every experiment, cell viability and cell count were determined using a Muse ${ }^{\circledR}$ Cell Analyzer (EMD Millipore, Billerica, MA, USA). Cells were adjusted to a concentration of $2 \times 10^{5}$ cells $/ \mathrm{mL}$ in culture medium, and $950 \mu \mathrm{L}$ of the suspension were seeded in each well of a TC 48-well plate (Sarstedt, Nümbrecht, Germany). Then, the wells were supplemented with $50 \mu \mathrm{L}$ of the sterile-filtered samples. After preincubation of cells with free hypericin, particle-bound hypericin or free hypericin in the presence of particles for 2 hours, the cells were incubated for 2 hours, while in the dark (plates were wrapped with aluminum foil) the cells were excited with a slimlite LED white light source (40 W/m², Kaiser, Buchen, Germany) for different time intervals $(0,5,10$, and 15 minutes $)$ to start the phototoxic reaction of hypericin, followed by incubation for 16, 24, and 48 hours. Subsequently, cells were mixed and $50 \mu \mathrm{L}$ of the cell suspension were taken out and incubated with 250 $\mu \mathrm{L}$ freshly prepared staining solution, consisting of $1 \mu \mathrm{L} /$ $\mathrm{mL}$ Hoe, $0.5 \mu \mathrm{L} / \mathrm{mL} \mathrm{AxV}$, and $0.4 \mu \mathrm{L} / \mathrm{mL}$ DiI in Ringer's solution for 20 minutes at $4^{\circ} \mathrm{C}$.

Flow cytometry was performed with a Gallios cytofluorometer (Beckman Coulter, Brea, CA, USA). Excitation for $\mathrm{AxV}$-Fitc was at $488 \mathrm{~nm}$, the Fitc fluorescence was recorded on an FL1 sensor (525/38 nm BP), the DiI fluorescence was excited at $638 \mathrm{~nm}$ and recorded on an FL6 sensor (675/ $20 \mathrm{~nm} \mathrm{BP}$ ), and the Hoechst 33342 fluorescence was excited at $405 \mathrm{~nm}$ and recorded on an FL9 sensor (430/40 nm BP). Electronic compensation was used to eliminate bleed through fluorescence. Data analysis was performed with Kaluza software version 2.0 (Beckman Coulter).

Hoe has been used to differentiate between cells (Hoe positive) and particles (Hoe negative). DiI was added to measure mitochondrial membrane potential in viable (DiI positive) as well as apoptotic and necrotic cells (both DiI 
negative). AxV serves as additional cell viability marker (AxV negative: viable; $\mathrm{AxV}$ positive: apoptotic/necrotic). During preparation steps, excitation by any ambient light was reduced to a minimum. All experiments were performed in triplicates and the results were averaged. The statistical significance of comparisons with the untreated control was investigated using Student's $t$-test in Excel (Microsoft Corporation, Redmond, WA, USA) $(* P<0.05$, ** $P<0.005$, and $* * * P<0.0005)$.

\section{In vitro ROS determination}

The amount of hypericin-produced ROS was determined using the fluorescence dye DCFH-DA. DCFH-DA was then incubated with the cells $\left(2 \times 10^{5}\right.$ cells $\left./ \mathrm{mL}\right)$ in a concentration of $20 \mu \mathrm{M}$ for 30 minutes in the dark at $37^{\circ} \mathrm{C}$ to ensure cell penetration. After that, cells were washed once and taken up in PBS. Suspensions $(950 \mu \mathrm{L})$ were pipetted into each well of a 48 -well plate and $50 \mu \mathrm{L}$ of free hypericin, particle-bound hypericin, as well as a free hypericin in the presence of SPION ${ }^{\mathrm{CMD}}$ were added to a drug concentration of $0.2 \mu \mathrm{g} / \mathrm{mL}$ and incubated for further 2 hours. Afterward, cells were excited with the LED white light source for 60 seconds. After further incubation for 5, 45, and 85 minutes, $300 \mu \mathrm{L}$ of each well were taken out and analyzed in flow cytometry. DCFH was excited at $488 \mathrm{~nm}$ and its fluorescence was recorded on an FL1 sensor (525/38 nm BP). The corresponding cell viability was determined by morphological cell analysis in a flow cytometer: the forward scatter, which is a measure for the size of the cell and can be used to determine between cell and nanoparticles, is plotted against the side scatter, which stands for the granularity of the cells. Experiments were performed in quadruplicates and the results were averaged. The statistical significance of comparisons with the untreated control was investigated using Student's $t$-test in Excel (Microsoft Corporation) $(* P<0.05, * * P<0.005$, and $* * * P<0.0005)$.

\section{Results and discussion}

\section{Structural characterization of SPION ${ }^{\text {CMD-Hyp }}$}

We first investigated the change in size and $\zeta$ potential after each preparation step of the particles, which is summarized in Table 1. SPION ${ }^{\text {DEX }}$, which is the building block of our system, has a hydrodynamic size of approximately $56.3 \pm 1.2 \mathrm{~nm}$ and a relatively uncharged surface with a $\zeta$ potential of $-5.3 \pm 0.3 \mathrm{mV}$. After the functionalization process, the hydrodynamic size is increased to $66.4 \pm 2.2 \mathrm{~nm}$. Due to the anionic character of carboxyl groups, which are introduced to the particle surface, the $\zeta$ potential is
Table I Particle sizes (volume mean diameter) and $\zeta$ potential in water at $\mathrm{pH} 7$

\begin{tabular}{|c|c|c|}
\hline Particle & $\begin{array}{l}\text { Hydrodynamic diameter } \\
\text { by volume }[\mathrm{nm}]\end{array}$ & $\begin{array}{l}\zeta \text { potential } \\
{[\mathrm{mV}]}\end{array}$ \\
\hline SPIONDEX & $56.3 \pm 1.2$ & $-5.3 \pm 0.5$ \\
\hline SPIONCMD & $66.4 \pm 2.2$ & $-35.9 \pm 1.1$ \\
\hline SPION CMD-Hyp & $84.5 \pm 0.3$ & $-40.7 \pm 1.5$ \\
\hline
\end{tabular}

Abbreviations: SPION ${ }^{D E X}$, dextran-coated SPIONs; SPION ${ }^{C M D}$, functionalized dextran-coated SPIONs; SPION, superparamagnetic iron oxide nanoparticle; SPION ${ }^{\text {CMD -Hyp }}$, hypericin linked to SPION ${ }^{\text {CMD }}$.

decreased to $-35.9 \pm 1.1 \mathrm{mV}$. The linkage between hypericin and SPION ${ }^{\text {CMD }}$ was achieved via GA, which changed the $\zeta$ potential to $-40.7 \pm 0.2 \mathrm{mV}$ and increased the hydrodynamic size to $84.5 \pm 0.3 \mathrm{~nm}$. The obtained particles did not show any sign of precipitation after 12 weeks of storage.

Besides the change in $\zeta$ potential, the success of carboxymethylation of the dextran coating on the particles is also demonstrated in the fourier transform infrared spectra (Figure 2A). Both SPION ${ }^{\text {DEX }}$ and SPION ${ }^{\text {CMD }}$ exhibit a strong peak at $600 \mathrm{~cm}^{-1}$ that can be attributed to $\mathrm{Fe}-\mathrm{O}$ surface vibrations. ${ }^{28}$ The presence of dextran can be ascertained by characteristic $\alpha$-glucopyranose ring deformation modes at frequencies of 765,845 , and $914 \mathrm{~cm}^{-1}$. Absorption bands at $1,000-1,150 \mathrm{~cm}^{-1}$ correspond to $\mathrm{C}-\mathrm{O}-\mathrm{C}$ vibrations and peaks at $1,040-1,150 \mathrm{~cm}^{-1}$ to $\mathrm{C}=\mathrm{O}$ vibrational modes. ${ }^{29}$ In addition, $\mathrm{C}-\mathrm{H}$ peaks of dextran were produced in a range of 1,250-1,460 $\mathrm{cm}^{-1}$ and further at around the frequency of $2,900 \mathrm{~cm}^{-1} \cdot{ }^{30}$ Absorption bands at 1,640 and 3,400 $\mathrm{cm}^{-1}$ are visible due to $\mathrm{O}-\mathrm{H}$ deformation and stretching modes of hydroxyl groups, related to the dextran coating and physical adsorbed water. ${ }^{30}$ After functionalization, the particles show new bands at $1,720 \mathrm{~cm}^{-1}$ and $1,640 \mathrm{~cm}^{-1}$, which correspond to $\mathrm{C}=\mathrm{O}$ stretches of carboxylic acid, and prove the success of the particle functionalization. After binding hypericin to the particles via GA, the peak ratios in the range between 1,800 and 1,200 $\mathrm{cm}^{-1}$ change (Figure 2B). The main differences in the spectra are the reduction of the peak at $1,600 \mathrm{~cm}^{-1}$ and the increase in the peak at $1,720 \mathrm{~cm}^{-1}$, which can also be attributed to $\mathrm{C}=\mathrm{O}$ stretches by hypericin. However, GA molecules, which are not involved in the hypericin binding, might also contribute to the band changes.

In order to quantify the amount of hypericin, which is coupled to the particles, an HPLC-MS quantification method was developed. An exemplary chromatogram of hypericin with the aforementioned conditions is depicted in Figure 3A. The peak has a retention time of 2.4 minutes and a slight tailing. Figure $3 \mathrm{~B}$ shows that there is a distinct linear correlation between the area under the curve and the 

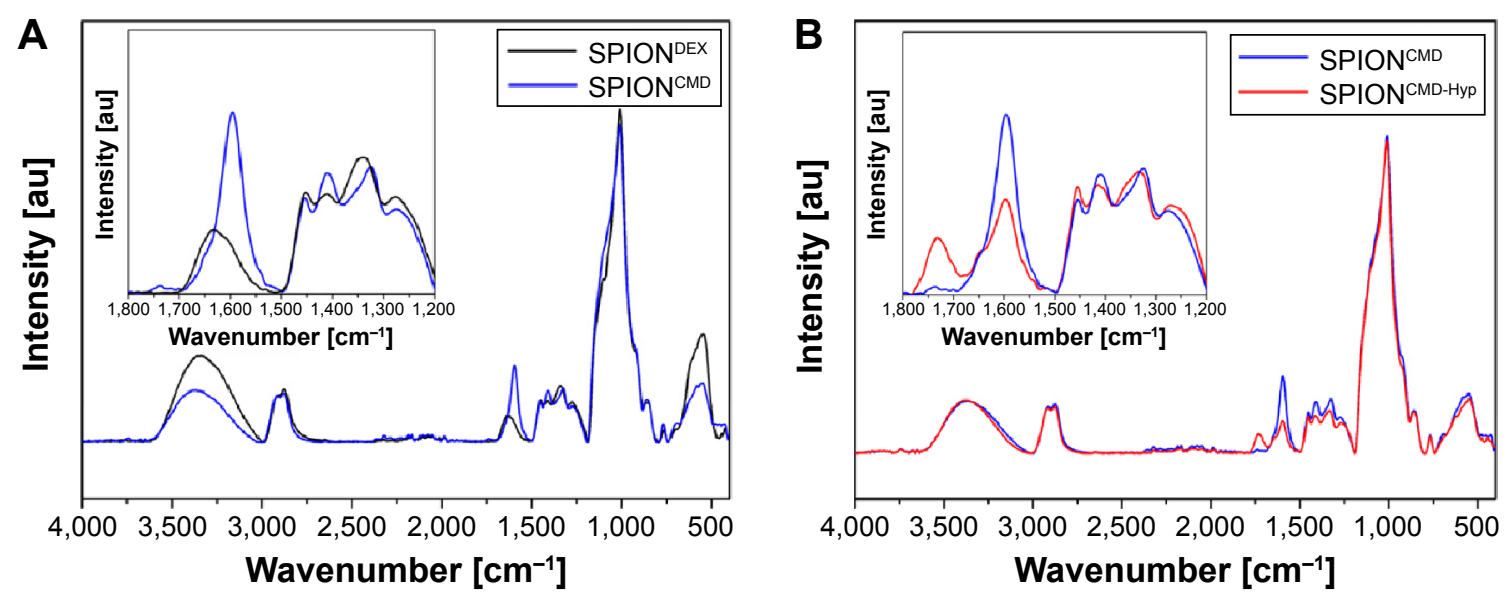

Figure 2 FT-IR spectra demonstrate the success of the functionalization of SPION ${ }^{\text {CMD }}$.

Notes: The inset shows the introduction of peaks at 1,720 and I,600 $\mathrm{cm}^{-1}$, which can be contributed to carboxyl groups (A). The spectra for SPIONCMD-Hyp shows changes in relative peak intensities, which can be attributed to the linkage of hypericin and glutaraldehyde; the inset shows magnification of the important wavenumber range (B).

Abbreviations: FT-IR, fourier transform infrared; SPION ${ }^{\text {CMD }}$, functionalized dextran-coated SPIONs; SPION, superparamagnetic iron oxide nanoparticle; SPION ${ }^{\text {CMD-Hyp, }}$ hypericin linked to SPIONCMD; SPION ${ }^{\text {DEX }}$, dextran-coated SPIONs; au, arbitrary unit.

hypericin concentration in the concentration range between 25 and $2,000 \mathrm{ng} / \mathrm{mL}$ with an $R^{2}=0.9993$. With this assay, the hypericin concentration of SPION ${ }^{\text {CMD-Hyp }}$ was determined as $6.9 \pm 0.8 \mu \mathrm{g} / \mathrm{mL}$ and in relation to the iron concentration it is $6.7 \pm 0.5 \mu \mathrm{g}$ hypericin/mg iron, which is high enough for further biological tests. ${ }^{31,32}$ Washing of the particles 12 weeks after fabrication and remeasuring the hypericin concentration resulted in similar contents, proving that the particles do not show drug leakage over the examined time period.

Overview TEM images of SPION ${ }^{\text {CMD }}$ and SPION ${ }^{\text {CMD-Hyp }}$ are depicted in Figure 4. Both samples show agglomeration of round iron oxide nanoparticles. The sizes of the clusters are consistent with dynamic light scattering experiments. Figure 5 displays the size distribution of the individual iron oxide cores which are the building blocks for the agglomerates. The distribution was derived from measuring 200 particles within TEM pictures (data not shown) with the software ImageJ. The sizes for SPIONCMD ranged from 3.0 to $9.0 \mathrm{~nm}$ and had a mean value of $4.5 \pm 1.0 \mathrm{~nm}$. SPION ${ }^{\text {CMD-Hyp }}$ has a similar distribution in the range between 3.0 and $10.0 \mathrm{~nm}$, with a mean value of $4.6 \pm 1.0 \mathrm{~nm}$. It can be concluded that the core size distributions for both samples were quite narrow and in the same order of magnitude. These values are in good agreement for dextran-coated SPIONs in the literature. ${ }^{26,33,34}$

Examination of the crystalline structure and the crystallite size were performed by recording an XRD pattern of SPION ${ }^{\text {CMD-Hyp }}$, which is depicted in Figure 6. Occurring peaks are characteristic for the face-centered cubic spinel structure
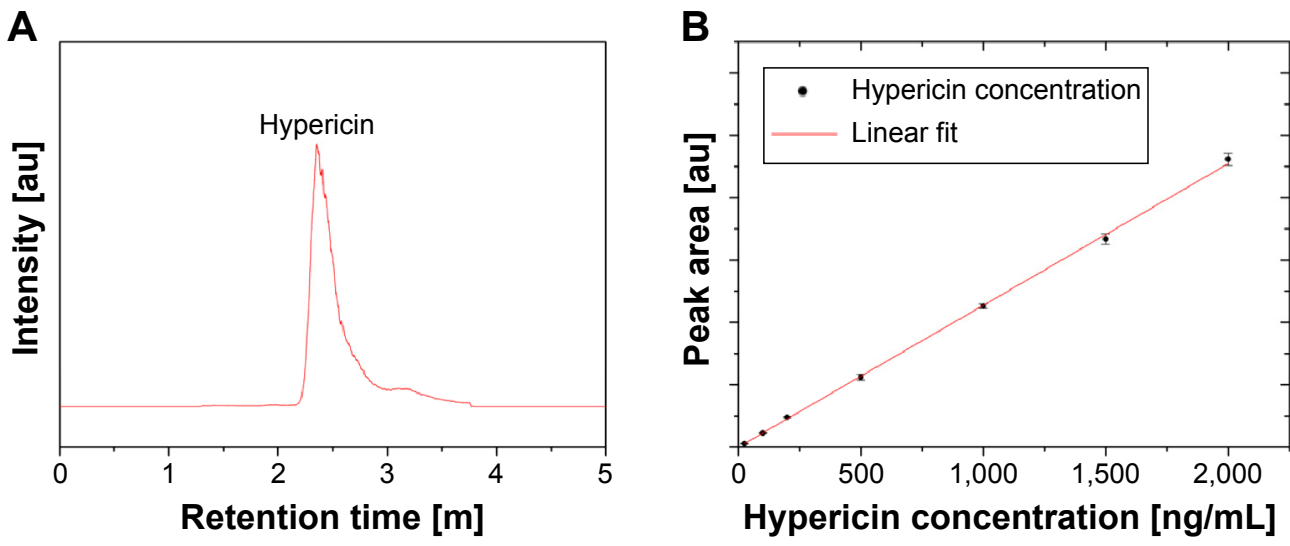

Figure 3 Exemplary HPLC ESI-MS chromatogram of hypericin (A). Linear calibration curve $\left(R^{2}=0.9993\right)$ for the determination of the particles' hypericin concentration $(\mathbf{B})$. Abbreviations: HPLC ESI-MS, high-performance liquid chromatography combined with an electrospray-ionization mass spectrometer; $\mathrm{m}$, minutes. 

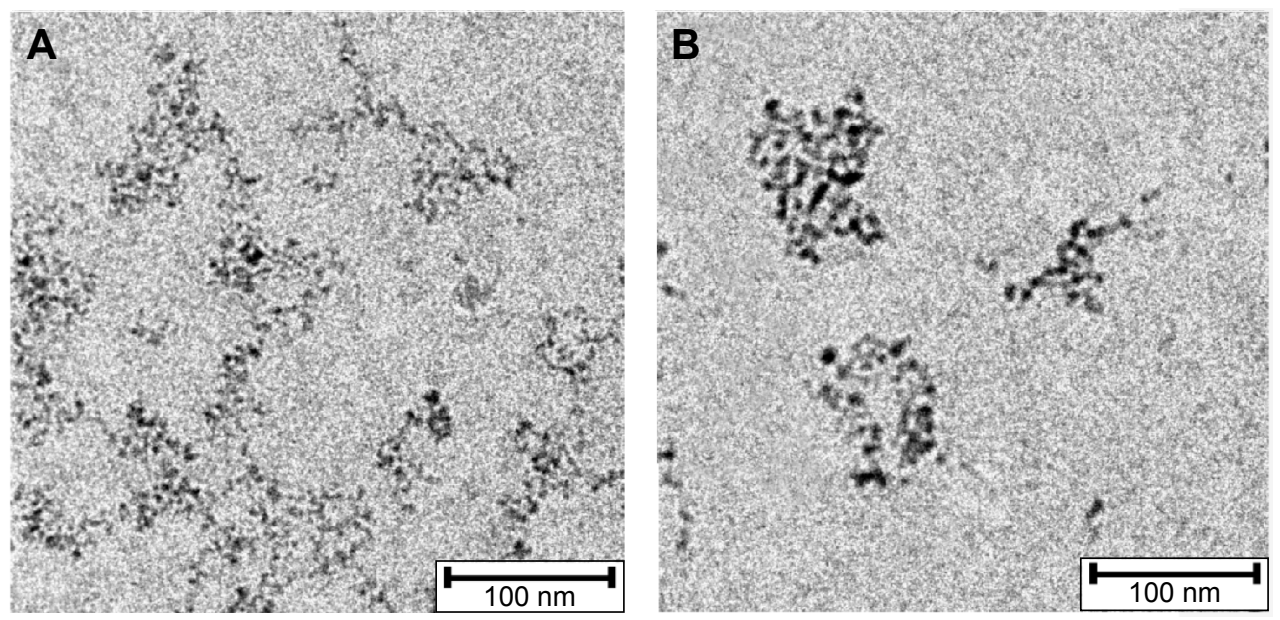

Figure 4 Overview TEM image of SPION ${ }^{\text {CMD }}(\mathbf{A})$ and SPION ${ }^{\text {CMD -Hyp }}$ (B) particles show agglomerates of SPIONs.

Abbreviations: TEM, transmission electron microscopy; SPION ${ }^{\text {CMD }}$, functionalized dextran-coated SPIONs; SPION, superparamagnetic iron oxide nanoparticle; SPION ${ }^{\text {CMD-Hyp, }}$ hypericin linked to SPION ${ }^{\text {CMD }}$.

of magnetite as well as maghemite, which only differ slightly. Thus, differentiation, whether magnetite, maghemite, or a combination of both has been formed, is not determinable only due to the XRD pattern. The major peak at $35.6^{\circ}$ refers to the (311) plane, while less marked peaks at $30.3^{\circ}(220), 43.4^{\circ}$ (400) $57.3^{\circ}(511)$, and $62.7^{\circ}(440)$ indicate a small crystallite size. ${ }^{35,36}$ Taking Bragg's law (Equation 1) into account, the interplanar spacing $d_{h k l}$, corresponding to the (311) plane, can be calculated with its peak position to $d_{h k l}=0.25240 \mathrm{~nm}$. By applying this result in Equation 2, the lattice parameter $a$ can be determined to $a=0.83713 \mathrm{~nm}$. In comparison with literature values for magnetite $(a=0.83967 \mathrm{~nm})$ and maghemite $(a=0.83457 \mathrm{~nm})$, the lattice parameter is located right between both iron oxide forms. ${ }^{37}$ Based on this result, a definite determination, whether magnetite or maghemite is formed, cannot be done. However, it can be assumed that a mixture of both is present in the sample. It is thinkable that magnetite has been formed during precipitation under inert gas, but even storage at $4^{\circ} \mathrm{C}$ of the particles enables oxidation and hence partial formation of maghemite..$^{38}$ Moreover, the crystallite size can be estimated with the full width at a half maximum of the (311) peak by applying Equation 3 . This results in $d_{\mathrm{XRD}} \approx 5 \mathrm{~nm}$ for the SPION ${ }^{\text {CMD-Hyp }}$ sample and is in line with the mean value of the size distribution, which was acquired from TEM images.

\section{Biological characterization of SPION ${ }^{\text {CMD-Hyp }}$}

The toxicological impact of SPION ${ }^{\text {CMD }}$, SPION ${ }^{\text {CMD-Hyp }}$, and hypericin alone on Jurkat cells was determined using two fluorescent viability markers in flow cytometry. Healthy
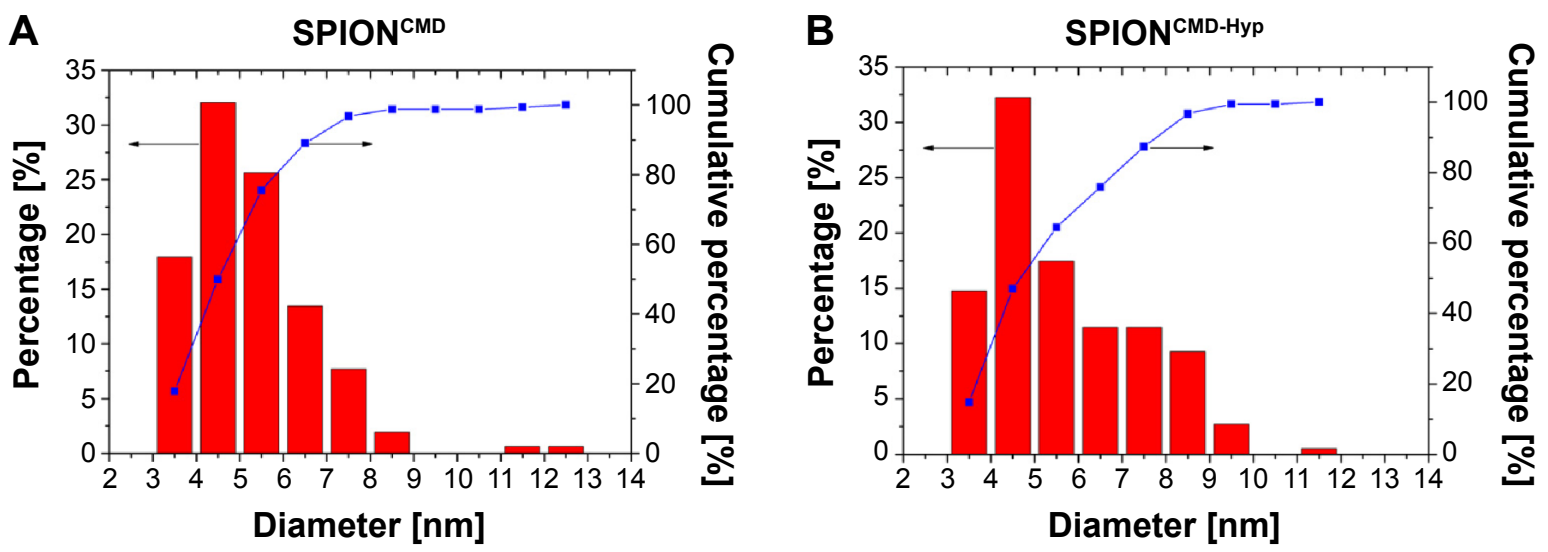

Figure 5 Magnetite particle distributions derived from measuring 200 particles of TEM images with the software ImageJ.

Notes: The sizes for SPION ${ }^{\text {CMD }}$ ranged from 3.0 to $9.0 \mathrm{~nm}$ and had a mean value of $4.5 \pm 1.0 \mathrm{~nm}(\mathbf{A})$. The sizes for SPION ${ }^{\mathrm{CMD}-H y p}$ ranged from 3.0 to I0.0 nm and had a mean value of $4.6 \pm 1.0 \mathrm{~nm}(\mathbf{B})$.

Abbreviations: TEM, transmission electron microscopy; SPION ${ }^{\text {CMD }}$, functionalized dextran-coated SPIONs; SPION, superparamagnetic iron oxide nanoparticle; SPION ${ }^{\text {CMD-Hyp, }}$ hypericin linked to SPION ${ }^{\text {MDD }}$. 


\section{SPION ${ }^{\text {CMD-Hyp }}$}

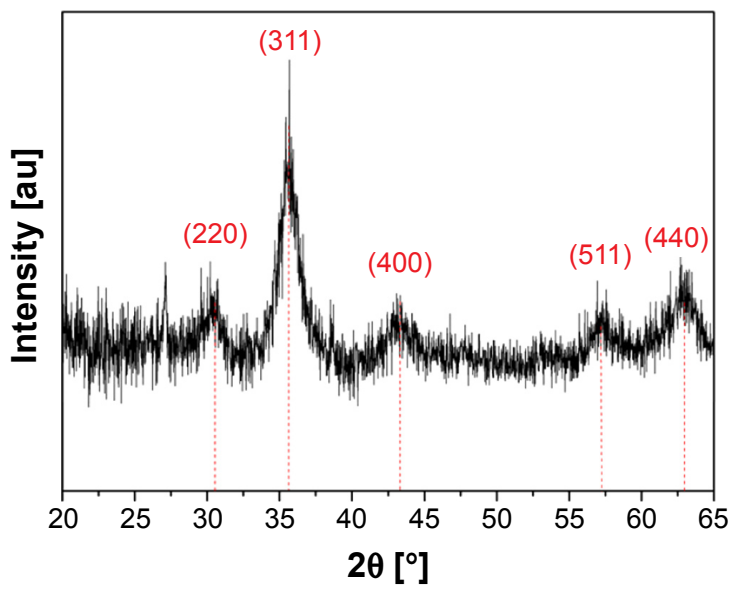

Figure 6 XRD pattern of SPION ${ }^{\text {MDD-Hyp }}$ exhibits typical peaks for the spinel structure of magnetite.

Note: The high noise is typical for nanocrystallites.

Abbreviations: XRD, X-ray diffraction; SPION ${ }^{\text {CMD }}$, functionalized dextran-coated SPIONs; SPION, superparamagnetic iron oxide nanoparticle; SPION NMD-Hyp, hypericin linked to SPION ${ }^{\text {CMD }}$.

cells exhibit a proton gradient of the inner mitochondrial plasma membrane, which generates the conversion from adenosine diphosphate to adenosine triphosphate. Therefore, DiI - a compound that penetrates the cytosol of the cells and accumulates in the active and vital mitochondria - was used to determine this membrane potential. A decrease in this potential is an indicator for apoptosis and necrosis. ${ }^{39}$ On the other hand, $\mathrm{AxV}$ serves as an alternative marker for dying and dead cells. AxV binds phosphatidylserine, which is accessible in apoptotic cells due to exposition on the outer layer of the plasma membrane and in necrotic cells due to rupture of the plasma membrane. Viable cells, in contrast, have an asymmetric plasma membrane with phosphatidylserine located on the inner side and not accessible for AxV binding. Usually, $\mathrm{AxV}$ is combined with propidium iodide, making it possible to differentiate between apoptotic and necrotic cells, but since the emission wavelength of propidium iodide $(620 \mathrm{~nm})$ overlaps by the emission peak of hypericin ( $\sim 600$ $\mathrm{nm})$, it is not used in our experiments. ${ }^{39}$

First of all, free hypericin was used as proof of principle for the phototoxicity of hypericin after light irradiation on Jurkat cells. Jurkat cells were treated with $0,0.1,0.2$, and $0.3 \mu \mathrm{g} / \mathrm{mL}$ hypericin and exposure time was $0,5,10$, and 15 minutes. Figure 7A exemplarily shows the results for the DiI staining 24 hours after exposure. Both the experiments with DiI and AxV (data not shown) indicate that in the absence of light, hypericin does not display any toxic effects independent from the incubation time, confirming hypericin's negligible dark toxicity ${ }^{40}$ However, a concentration and exposure time-dependent increase in cytotoxicity can be clearly observed. With 15 minutes of light exposure, all hypericin concentrations cause complete cell death, whereas with shorter light exposure (5 and 10 minutes) not all cells are killed. In the samples with 5-minute exposure, a clear dosedependent cytotoxic effect of the hypericin can be observed. Interestingly, after incubation for 48 hours, proliferation of the surviving cells can be observed (Figure 7B) underlining the importance of initially high tumor cell killing rates in cancer therapy, especially for the fact that apoptotic cell death is immunologically silent and factors released from apoptotic cells might foster the compensatory proliferation of the surviving cells causing tumor cell repopulation. ${ }^{41}$

Based on these data for the following experiments, an intermediate hypericin concentration of $0.2 \mu \mathrm{g} / \mathrm{mL}$ was selected to investigate cytotoxic capacity of nanoparticle

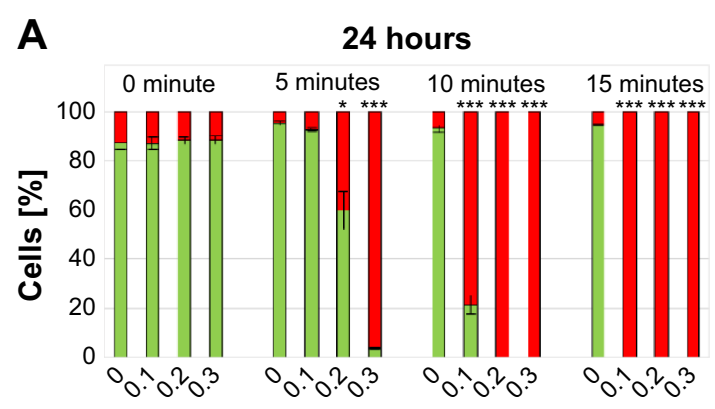

Hypericin concentration $[\mu \mathrm{g} / \mathrm{mL}]$
B

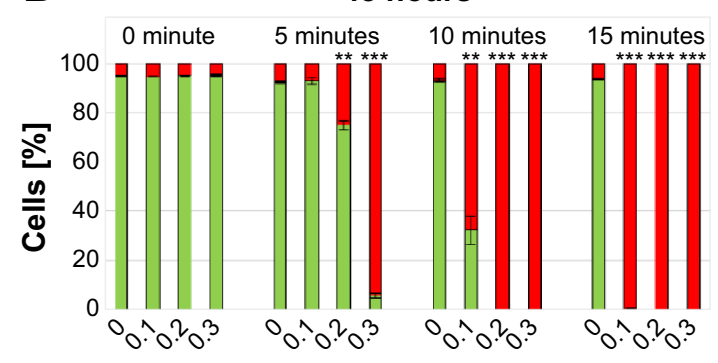

Hypericin concentration $[\mu \mathrm{g} / \mathrm{mL}]$

$\square$ Dil $-\square \mathrm{Dil}+$

Figure 7 Cell death of Jurkat cells determined by Dil staining 24 hours (A) and 48 hours (B) after treatment with hypericin in different concentrations.

Notes: Dil-positive cells were considered viable, Dil-negative cells were considered dying/dead. Without illumination hypericin shows no toxicity, whereas with increased exposure time $(0,5,10$, and 15 minutes) as well as concentration $(0,0.1,0.2$, and $0.3 \mu \mathrm{g} / \mathrm{mL})$ cell death can be observed. Figures show the mean values of triplicates with standard deviations. The statistical significance of comparisons with the untreated control was investigated using Student's $t$-test in Excel (Microsoft Corporation, Redmond, WA, USA) ( $* P<0.05, * * P<0.005$, and $* * * P<0.0005)$.

Abbreviation: Dil, hexamethylindodicarbo-cyanine iodide. 
loaded with hypericin. Free hypericin, SPION ${ }^{\text {CMD-Hyp }}$ (corresponding iron concentration: $30 \mu \mathrm{g} / \mathrm{mL}$ ), and SPIONCMD in the presence of free hypericin were incubated with Jurkat cells and illuminated for the same times as aforementioned. Water and SPIONCMD served as controls. Figure $8 \mathrm{~A}$ shows exemplary results for DiI staining 24 hours after exposure (corresponding $\mathrm{AxV}$ data are shown in Figure $\mathrm{S} 1$ ). In line with the experiment before, in the presence of hypericin and the absence of light cell remained viable, whereas hypericin in the presence of light induced cell death in an exposure time-dependent manner. Unloaded SPIONs (SPION ${ }^{\mathrm{CMD}}$ ) did not induce cell death at all.

Comparing the cytotoxic effect of free hypericin (Нyp and SPION ${ }^{\text {CMD }}+$ Hyp) and particle-bound hypericin (SPION ${ }^{\mathrm{CMD}-H y p}$ ), free hypericin showed a stronger cytotoxic effect. In contrast, the presence of SPIONs in the free hypericin solution (SPION ${ }^{\mathrm{CMD}}+\mathrm{Hyp}$ ) did not reduce the cytotoxic effect, indicating that binding of hypericin to the particles and not quenching of light is responsible for a lower cytotoxicity of SPION-bound hypericin. Again, prolonged incubation of cells after treatment showed proliferation of the surviving cells in the presence of free hypericin as well as in the presence of SPION ${ }^{\text {CMD-Hyp (Figure 8B). }}$

In order to prove that the cytotoxic effects can be attributed to the ROS formation an assay with the hydrophobic and nonfluorescent DCFH-DA molecule is used. It is able to penetrate into cells, where intracellular esterases hydrolyze it to the nonfluorescent dichlorofluorescein
(DCFH). In the presence of ROS, DCFH is oxidized to the fluorescent dichlorofluorescein (FDCF), which can be detected by flow cytometry to quantify the amount of produced ROS. ${ }^{42}$ For the experiments, an intermediate hypericin concentration of $0.2 \mu \mathrm{g} / \mathrm{mL}$ was used. For previous phototoxicity investigations, cells were incubated in FCS containing culture medium, whereas for ROS determination using DCFH-DA cells were incubated in PBS. Preliminary tests showed that the change of the suspension media increases the sensitivity of the cells toward the treatment, and therefore the irradiation time had to be reduced to 1 minute under these conditions. Figure 9 shows exemplary results in 5 minutes after light exposure. The fluorescence signal indicating the ROS generation was normalized to the control.

Without illumination, no increase in the FDCF fluorescence signal is detected and the cell viability is unchanged. However, after 1 minute light exposure, all samples with hypericin showed an increase in FDCF fluorescence indicating the generation of ROS. It is noteworthy that even the particles without hypericin produced a low amount of ROS, which might be due to the Fenton reaction that occurs by availability of $\mathrm{Fe}^{2+}$ of the particles in the presence of hydrogen peroxide. ${ }^{43}$ As a consequence, 5 minutes of incubation after light exposure, the FDCF intensity of SPIONCMD + hypericin is approximately the sum of the intensities of pure hypericin and SPION ${ }^{\text {CMD }}$ specimens. The intensity of SPION ${ }^{\text {CMD-Hyp }}$ is higher compared to SPION ${ }^{\mathrm{CMD}}$, but lower compared to the other

B

A

24 hours

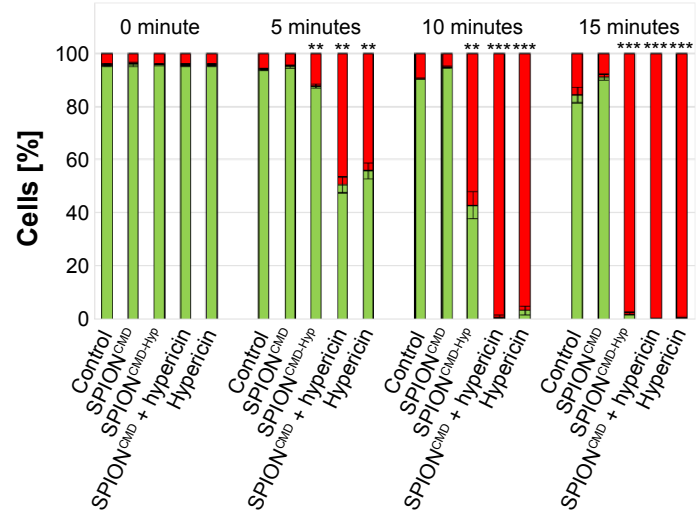

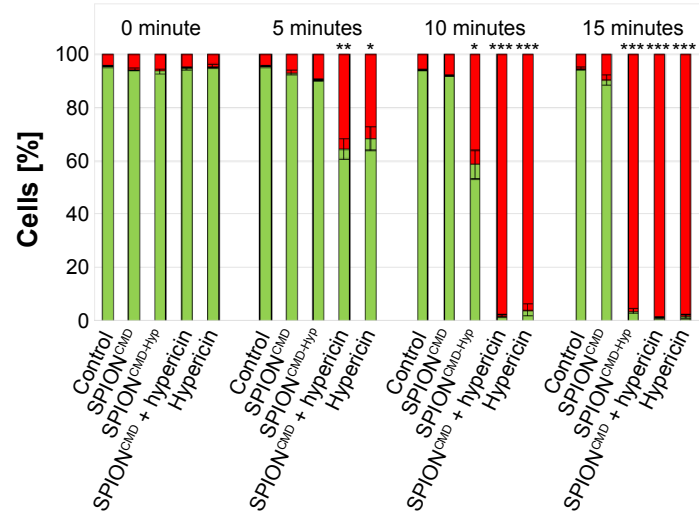

$\square$ Dil- $\square$ Dil+

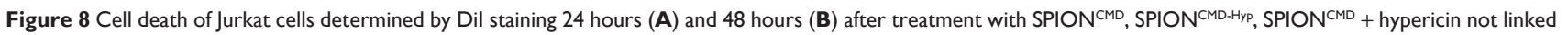
to the particles as well as hypericin alone at a hypericin concentration of $0.2 \mu \mathrm{g} / \mathrm{mL}$.

Notes: Dil-positive cells were considered viable, Dil-negative cells were considered dying/dead. Without illumination all samples show no toxicity, whereas with increased exposure time $(0,5,10$, and 15 minutes) cell death can be observed. Figures show the mean values of triplicates with standard deviations. The statistical significance of comparisons with the untreated control was investigated using Student's $t$-test in Excel (Microsoft Corporation, Redmond, WA, USA) $(* P<0.05$, $* * P<0.005$, and $* * * P<0.0005)$. Abbreviations: Dil, hexamethylindodicarbo-cyanine iodide; SPION ${ }^{C M D}$, functionalized dextran-coated SPIONs; SPION, superparamagnetic iron oxide nanoparticle; SPION ${ }^{\text {CMD-Hyp }}$, hypericin linked to SPION ${ }^{\text {CMD }}$. 
A

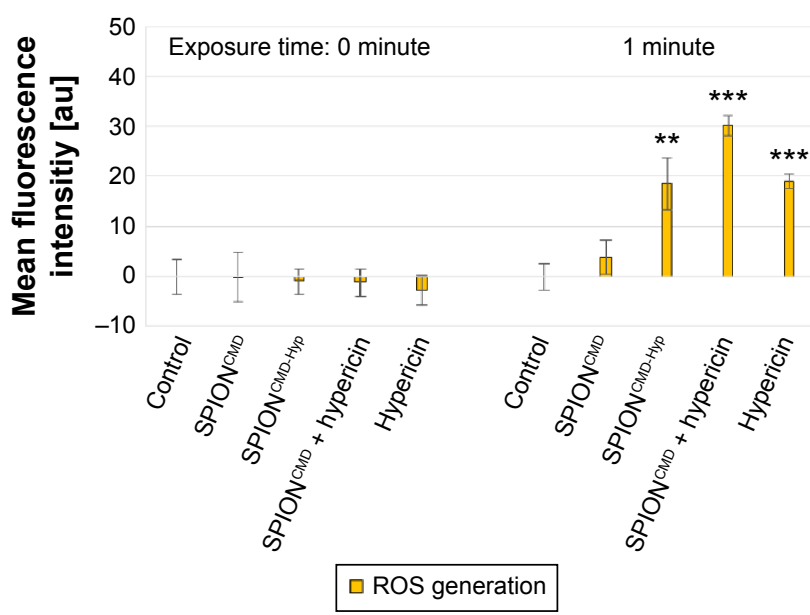

B

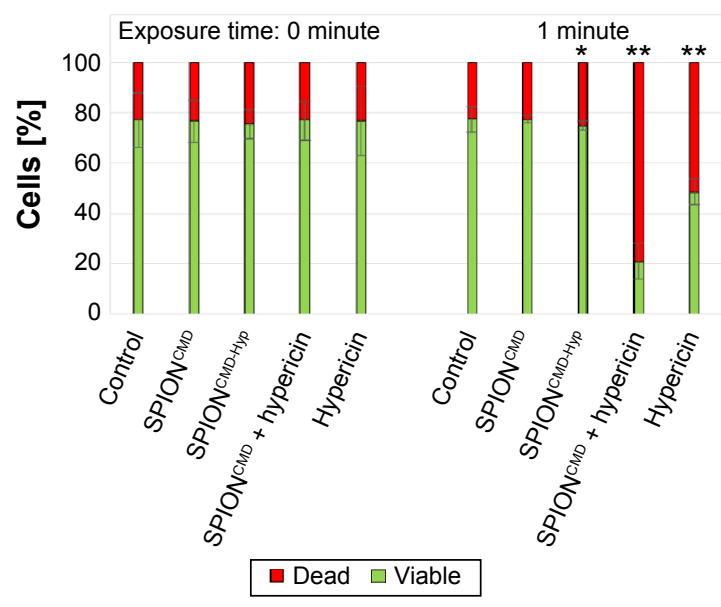

Figure 9 Determination of ROS generation (A) and corresponding cell death (B).

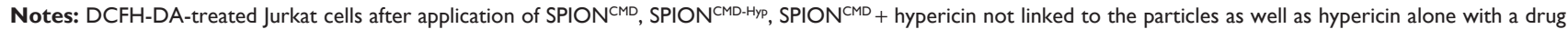
concentration of $0.2 \mu \mathrm{g} / \mathrm{mL}$ and exposure time of I minute. Cell viability was determined by morphological cell analysis. After incubation for 5 minutes the hypericin samples showed ROS generation and correspondent cell death, whereas hypericin-bound nanoparticles without illumination did not generate ROS. Figures present the mean value of quadruplicates with standard deviations. The statistical significance of comparisons with the untreated control was investigated using Student's $t$-test in Excel (Microsoft Corporation, Redmond, WA, USA) $(* P<0.05$, **P<0.005, and **** $<0.0005)$.

Abbreviations: DCFH-DA, 2',7'-dichlorofluorescein diacetate; SPION ${ }^{\text {CMD }}$, functionalized dextran-coated SPIONs; SPION, superparamagnetic iron oxide nanoparticle; SPION ${ }^{\text {CMD-Hyp }}$, hypericin linked to SPION ${ }^{\text {CMD; }}$ ROS, reactive oxygen species; au, arbitrary unit.

ones which is in agreement with the slower kinetics in the toxicological investigations. Furthermore, already 5 minutes after light exposure for 1 minute, cell death was induced as determined by characteristic morphological alterations of the cells, leading to the assumption that the predominant cell death mechanism is necrosis, because apoptosis is a more time-consuming process. ${ }^{44}$ With prolonged incubation after light exposition, the FDCF fluorescence signal of the samples with free hypericin decreases parallel with increasing cell death rates, whereas the SPION-bound hypericin produces a constant FDCF signal with lower cell death rates. This might be due to faster intracellular uptake and abreaction of free hypericin compared to nanoparticle bound hypericin.

\section{Conclusion}

In this project, dextran-coated and functionalized SPIONs, loaded with a sufficient amount of hypericin, were successfully synthesized for the first time. The particles were stable in water and PBS for several weeks, without any sign of agglomeration. The evaluation of the phototoxic behavior of the hypericin-bound particles was performed with the nonadherent Jurkat cell line by investigating the viability of cells via DiI and AxV staining and flow cytometry. The experiment revealed that pure nanoparticles as well as hypericin were not toxic for the cells in the absence of light illumination, whereas drug-loaded particles induced cell death in a concentration and exposure time-dependent manner. Comparison of nanoparticle-loaded hypericin to the controls treated with free hypericin indicated a weaker cytotoxic impact that can be explained by reducing effects of drug coupling to particles. This difference can still be compensated by adjusting the irradiation time. Furthermore, with a DCFH-DA assay, the origin of the cytotoxic behavior could be attributed to the generation of ROS. In conclusion, the combination of dextran-coated SPIONs loaded with hypericin represents a promising approach to be used in combined MDT and PDT for cancer therapy.

\section{Acknowledgments}

The authors are grateful to the Bavarian State Ministry of the Environment and Consumer Protection, the Margarete Ammon Stiftung, and to the DFG Cluster of Excellence - Engineering of Advanced Materials (EAM) for their support. We further acknowledge support by Deutsche Forschungsgemeinschaft and Friedrich-Alexander-Universität Erlangen-Nürnberg within the Open Access Publishing funding program.

\section{Disclosure}

The authors report no conflicts of interest in this work.

\section{References}

1. Tietze R, Lyer S, Durr S, Alexiou C. Nanoparticles for cancer therapy using magnetic forces. Nanomedicine (Lond). 2012;7(3):447-457.

2. Alexiou C, Tietze R, Schreiber E, et al. Cancer therapy with drug loaded magnetic nanoparticles - magnetic drug targeting. J Magn Magn Mater. 2011;323(10):1404-1407.

3. Tietze R, Jurgons R, Lyer S, et al. Quantification of drug-loaded magnetic nanoparticles in rabbit liver and tumor after in vivo administration. $J$ Magn Magn Mater. 2009;321(10):1465-1468. 
4. Alexiou C, Diehl D, Henninger P, et al. A high field gradient magnet for magnetic drug targeting. IEEE Trans Appl Supercond. 2006;16(2): 1527-1530.

5. Seliger $\mathrm{C}$, Jurgons $\mathrm{R}$, Wiekhorst $\mathrm{F}$, et al. In vitro investigation of the behaviour of magnetic particles by a circulating artery model. $J$ Magn Magn Mater. 2007;311(1):358-362.

6. Bealle G, Di CR, Kolosnjaj-Tabi J, et al. Ultra magnetic liposomes for $\mathrm{mr}$ imaging, targeting, and hyperthermia. Langmuir. 2012;28(32): 11834-11842.

7. Alexiou C, Tietze R, Schreiber E, Lyer S. Pharmakotherapie mittels nanomedizin. Onkologe. 2011;17(5):405-412.

8. Cheng L, Jin C, Lv W, Ding Q, Han X. Developing a highly stable PLGA-mPEG nanoparticle loaded with cisplatin for chemotherapy of ovarian cancer. PLoS One. 2011;6(9):e25433-e25433.

9. Tietze R, Lyer S, Durr S, et al. Efficient drug-delivery using magnetic nanoparticles - biodistribution and therapeutic effects in tumour bearing rabbits. Nanomed Nanotechnol Biol Med. 2013;9(7):961-971.

10. Janko C, Dürr S, Munoz L, et al. Magnetic drug targeting reduces the chemotherapeutic burden on circulating leukocytes. Int $J$ Mol Sci. 2013;14(4):7341-7355.

11. Dorniani D, Bin HMZ, Kura AU, Fakurazi S, Shaari AH, Ahmad Z. Preparation of $\mathrm{Fe}_{3} \mathrm{O}_{4}$ magnetic nanoparticles coated with gallic acid for drug delivery. Int J Nanomed. 2012;7:5745-5756.

12. Wahajuddin, Arora S. Superparamagnetic iron oxide nanoparticles: magnetic nanoplatforms as drug carriers. Int J Nanomed. 2012;7: 3445-3471.

13. Zhao Y, Dunnill $\mathrm{CW}$, Zhu Y, et al. Low-temperature magnetic properties of hematite nanorods. Chem Mater. 2007;19(4):916-921.

14. Shi S, Jia J-f, Guo X-k, et al. Toxicity of iron oxide nanoparticles against osteoblasts. J Nanopart Res. 2012;14(9):1091.

15. Lyer S, Tietze R, Jurgons R, et al. Visualisation of tumour regression after local chemotherapy with magnetic nanoparticles - a pilot study. Anticancer Res. 2010;30(5):1553-1557.

16. Alexiou C. Nanomedicine: basic and clinical applications in diagnostics and therapy. Else Kröner-Fresenius Symposium. Vol 2. Basel: Karger; 2011:154-163.

17. Lyer S, Tietze R, Dürr S, et al. Diagnostic imaging in cancer therapy with magnetic nanoparticles. In: Buzug TM, Borgert J, editors. Magnetic Particle Imaging. Vol. 140. Berlin, Heidelberg: Springer; 2012:199-203.

18. Brunke O, Odenbach S, Jurgons R, Alexiou C, Hilger I, Beckmann F Determination of the magnetic particle distribution in tumour tissue by means of x-ray tomography. J Phys Condens Matter. 2006;18(38): S2903.

19. Tietze R, Rahn H, Lyer S, et al. Visualization of superparamagnetic nanoparticles in vascular tissue using XmuCT and histology. Histochem Cell Biol. 2011;135(2):153-158.

20. Kim DK, Zhang Y, Voit W, Rao KV, Muhammed M. Synthesis and characterization of surfactant-coated superparamagnetic monodispersed iron oxide nanoparticles. J Magn Magn Mater. 2001;225(1-2):30-36.

21. Lee YT, Woo K, Choi KS. Preparation of water-dispersible and biocompatible iron oxide nanoparticles for MRI agent. IEEE Trans Nanotechnol. 2008;7(2):111-114.

22. Carmen Bautista M, Bomati-Miguel O, del Puerto Morales M, Serna CJ, Veintemillas-Verdaguer S. Surface characterisation of dextran-coated iron oxide nanoparticles prepared by laser pyrolysis and coprecipitation. J Magn Magn Mater. 2005;293(1):20-27.

23. Huynh R, Chaubet F, Jozefonvicz J. Carboxymethylation of dextran in aqueous alcohol as the first step of the preparation of derivatized dextrans. Die Angew Makromol Chem. 1998;254(1):61-65.

24. Karioti A, Bilia AR. Hypericins as potential leads for new therapeutics. Int J Mol Sci. 2010;11(2):562-594.

25. Wilson BC. Photodynamic therapy for cancer: principles. Can $J$ Gastroenterol. 2002;16(6):393-396.

26. Unterweger H, Tietze R, Janko C, et al. Development and characterization of magnetic iron oxide nanoparticles with a cisplatin-bearing polymer coating for targeted drug delivery. Int J Nanomed. 2014;9:3659-3676.
27. Dokuzovic L. Kolorimetrie-photometrie. Available from: http://www. lickl.net/doku/photo.pdf. 18-22. Accessed on Oct 23, 2013.

28. Shen M, Cai H, Wang Xea. Facile one-pot preparation, surface functionalization, and toxicity assay of APTS-coated iron oxide nanoparticles. Nanotechnology. 2012;23(10):105601.

29. Pretsch E, Bühlmann P, Badertscher M. Structure Determination of Organic Compounds - Tables of Spectral Data. Vol 4. Berlin Heidelberg: Springer-Verlag; 2009.

30. Jung CW. Surface properties of superparamagnetic iron oxide MR contrast agents: ferumoxides, ferumoxtran, ferumoxsil. Magn Reson Imag. 1995;13(5):675-691.

31. Zhang W, Anker L, Law RE, et al. Enhancement of radiosensitivity in human malignant glioma cells by hypericin in vitro. Clin Cancer Res. 1996;2(5):843-846.

32. Blank M, Kostenich G, Lavie G, Kimel S, Keisari Y, Orenstein A. Wavelength-dependent properties of photodynamic therapy using hypericin in vitro and in an animal model. Photochem Photobiol. 2002; 76(3):335-340.

33. Bogdanov AA Jr, Martin C, Weissleder R, Brady TJ. Trapping of dextran-coated colloids in liposomes by transient binding to aminophospholipid: preparation of ferrosomes. Biochim Biophys Acta. 1994; 1193(1):212-218

34. Pardoe H, Chua-anusorn W, St Pierre TG, Dobson J. Structural and magnetic properties of nanoscale iron oxide particles synthesized in the presence of dextran or polyvinyl alcohol. J Magn Magn Mater. 2001; 225(1-2):41-46.

35. Mascolo M, Pei Y, Ring T. Room temperature co-precipitation synthesis of magnetite nanoparticles in a large $\mathrm{pH}$ window with different bases. Materials. 2013;6(12):5549-5567.

36. Sun J, Zhou S, Hou P, et al. Synthesis and characterization of biocompatible $\mathrm{Fe}_{3} \mathrm{O}_{4}$ nanoparticles. J Biomed Mater Res Part A. 2007;80A(2): 333-341.

37. Cervellino A, Frison R, Cernuto G, Guagliardi A, Masciocchi N. Lattice parameters and site occupancy factors of magnetite-maghemite coreshell nanoparticles. A critical study. J Appl Crystallograp. 2014;47(5): 1755-1761.

38. Zaloga J, Janko C, Agarwal R, et al. Different storage conditions influence biocompatibility and physicochemical properties of iron oxide nanoparticles. Int J Mol Sci. 2015;16(5):9368-9384.

39. Munoz LE, Maueroder C, Chaurio R, Berens C, Herrmann M, Janko C. Colourful death: six-parameter classification of cell death by flow cytometry - dead cells tell tales. Autoimmunity. 2013;46(5):336-341.

40. Agostinis P, Vantieghem A, Merlevede W, de Witte PAM. Hypericin in cancer treatment: more light on the way. Int J Biochem Cell Biol. 2002;34:221-241.

41. Huang Q, Li F, Liu X, et al. Caspase 3-mediated stimulation of tumor cell repopulation during cancer radiotherapy. Nat Med. 2011;17(7): 860-866.

42. Barathan M, Mariappan V, Shankar EM, Abdullah BJ, Goh KL, Vadivelu J. Hypericin-photodynamic therapy leads to interleukin-6 secretion by HepG2 cells and their apoptosis via recruitment of $\mathrm{BH} 3$ interacting-domain death agonist and caspases. Cell Death Dis. 2013;4:e697.

43. Liu Q, Berchner-Pfannschmidt U, Möller U, et al. A Fenton reaction at the endoplasmic reticulum is involved in the redox control of hypoxiainducible gene expression. Proc Natl Acad Sci U S Am. 2004;101(12): 4302-4307.

44. Bonfoco E, Krainc D, Ankarcrona M, Nicotera P, Lipton SA. Apoptosis and necrosis: two distinct events induced, respectively, by mild and intense insults with N-methyl-D-aspartate or nitric oxide/superoxide in cortical cell cultures. Proc Natl Acad Sci U S Am. 1995;92(16): $7162-7166$. 


\section{Supplementary material}

A

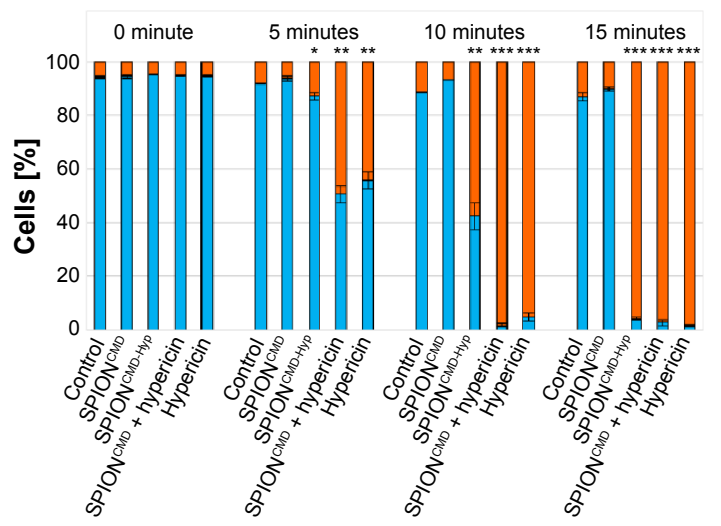

B

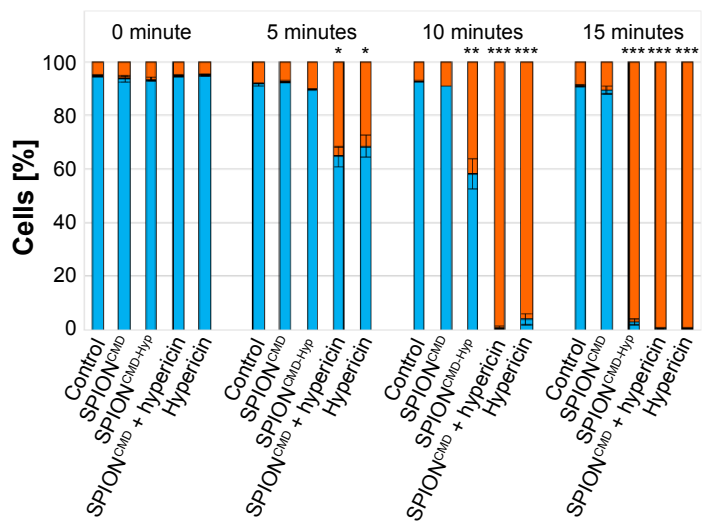

$\square \mathrm{AxV}+\square \mathrm{AxV}-$

Figure SI Cell death of Jurkat cells determined by AxV staining 24 hours $(\mathbf{A})$ and 48 hours $(\mathbf{B})$ after treatment with SPION ${ }^{\text {CMD }}$, SPION ${ }^{\text {CMD-Hyp }}$, and SPION ${ }^{\text {CMD }}+$ hypericin not linked to the particles as well as hypericin alone at a hypericin concentration of $0.2 \mu \mathrm{g} / \mathrm{mL}$.

Notes: AxV-negative cells were considered viable, AxV-positive cells were considered dying/dead. Without illumination all samples show no toxicity, whereas with increased exposure time $(0,5,10$, and 15 minutes) cell death can be observed. Figure shows the mean values of triplicates with standard deviations. The statistical significance of comparisons with the untreated control was investigated using Student's $t$-test in Excel (Microsoft Corporation, Redmond, WA, USA) $(* P<0.05$, $* * P<0.005$, and $* * * P<0.0005)$.

Abbreviations: AxV, Annexin V; SPION CMD, functionalized dextran-coated SPIONs; SPION, superparamagnetic iron oxide nanoparticle; SPIONCMD-Hyp, hypericin linked to SPION ${ }^{\text {CMD }}$.

\section{Publish your work in this journal}

The International Journal of Nanomedicine is an international, peerreviewed journal focusing on the application of nanotechnology in diagnostics, therapeutics, and drug delivery systems throughout the biomedical field. This journal is indexed on PubMed Central, MedLine, CAS, SciSearch $®$, Current Contents ${ }^{\circledR} /$ Clinical Medicine,
Journal Citation Reports/Science Edition, EMBase, Scopus and the Elsevier Bibliographic databases. The manuscript management system is completely online and includes a very quick and fair peer-review system, which is all easy to use. Visit http://www.dovepress.com/ testimonials.php to read real quotes from published authors. 